Acta Crystallographica Section D Biological

Crystallography

ISSN 0907-4449

\section{addenda and errata}

\title{
Description of ordered solvent molecules in a platinated decanucleotide duplex refined at $1.6 \AA$ resolution against experimental MAD phases. Addendum
}

\section{Franck Coste, ${ }^{a}$ William Shepard ${ }^{b}$ and Charles Zelwer ${ }^{a *}$}

${ }^{a}$ Centre de Biophysique Moléculaire, Centre National de la Recherche Scientifique, affiliated to the University of Orléans and to the Institut National de la Santé et de la Recherche Médicale, Rue Charles Sadron, 45071 Orléans CEDEX 2, France, and

bLaboratoire pour I'Utilisation du Rayonnement Electromagnétique, BP 34, Bâtiment 209d, Centre Universitaire Paris-Sud, 91898 Orsay CEDEX, France

An acknowledgment is published for the paper by Coste et al. [Acta Cryst. (2002) D58, 431-440]. The acknowledgement is as follows: This work was supported by grants from l'Association pour la Recherche sur le Cancer, and la Ligue Contre le Cancer du Loiret; $\mathrm{FC}$ was the recipient of a $\mathrm{PhD}$ fellowship from the Région Centre.

\section{References}

Coste, F., Shepard, W. \& Zelwer, C. (2002). Acta Cryst. D58, 431-440. 